\title{
KEGAGALAN BADAN ANTIKORUPSI
}

Oleh Shohibul Anshor Siregar

Director of Global Supply Chain Compliance at International Rescue Committee, Michael Ndichu Kuria (2012), dalam sebuah tulisannya berjudul "Why do anti-corruption agencies fail?" memaparkan fakta mengejutkan tentang badan antikorupsi. Orang yang berpengalaman dalam bidang tugas konsultansi kontra-penipuan dan kontra-korupsi (terutama untuk wilayah Timur, Tengah dan Tanduk Afrika), ini mengemukakan bahwa sebagian besar dari 50 negara paling korup di dunia membanggakan setidaknya satu lembaga antikorupsi terpusat yang bertugas untuk mencegah, menyelidiki dan mengadili kasuskasus korupsi.

Pada pihak lain, 10 negara paling korup tidak memiliki lembaga terpusat semacam itu. Kelihatannya, kata orang yang mahir melakukan tinjauan kepatuhan anti-penyuapan, audit forensik, penyelidikan kecurangan dan kesalahan, tinjauan integritas, manajemen risiko kecurangan, tinjauan kepatuhan kebijakan pengadaan, dan penilaian kontrol, ini, ada korelasi negatif yang kuat antara kehadiran satu badan anti-korupsi pusat dan reduksi korupsi.

Apa yang dengan sangat meyakinkan dia simpulkan kemudian ialah bahwa pembentukan badan antikorupsi terpusat justru dengan sendirinya menciptakan iklim yang membuatnya terlalu mudah bagi politisi korup dan birokrat untuk menangkap organ-organnya. Karena itu pula sekaligus dengan enteng para koruptor mampu mencegahnya mencapai tujuan yang digembar-gemborkannya sendiri. Terlepas dari situasi betapa diharapkannya badan terpusat yang sangat istimewa itu menyelesaikan masalah, namun banyak bukti menunjukkan rakyat tetap tak pernah beranjak dari mimpi negara bersih korupsi.

Sepanjang telaahannya hanya ada sangat sedikit contoh agen antikorupsi terpusat yang berhasil memerangi korupsi di dunia ini, di antaranya termasuklah Singapura dan Hong Kong. Akan tetpi meskipun Michael Ndichu Kuria memberi catatan penting atas sukses kedua negara itu dalam memerangi korupsi, sesunggunya ia tak melupakan aspek khusus yang jarang diingat orang, yakni bahwa Singapura dan Hongkong itu adalah negara yang relatif kecil dan sangat urban. Succes story di negara kecil tak serta-merta dapat direplikasi sama di negara berbeda karakter.

Karena pengaruh cerita keberhasilan, tentu saja kemudian kedua negara itu dianggap menjadi model terbaik dan ketika ide itu menginspirasi sebuah negara lain membentuk badan antikorupsi, sejumlah negara pengekor itu pun melahirkan sesuatu yang kemiripannya dengan praktik di Singapura dianggap sangat penting, yakni badan antikorupsinya beroleh kekuasaan dan independensinya dari undangundang yang disahkan sebagai tanggapan atas skandal serius yang mengancam stabilitas pemerintah.

Diketahui bahwa Independent Commission Against Corruption (ICAC) di Hong Kong dibentuk sebagai tanggapan terhadap perselingkuhan Peter Godber 1974, sedangkan Corrupt Practices Investigation Bureau (CPIB) Singapura hanya diperkuat sebagai respon terhadap skandal tahun 1970an yang melibatkan petugas kepolisian dalam perdagangan narkotika. Mungkin sangat mirip dengan di negara lain tertentu lainnya, bahwa krisis semacam itu memang cukup memaksa pembuat kebijakan melahirkan lembaga anti-korupsi yang independen dari kepolisian manakala polisi dipandang benarbenar sudah begitu buruk.

Menurut Michael Ndichu Kuria, model badan antikorupsi terpusat telah gagal di berbagai negara seperti Afrika dan sebagian besar dunia ketiga lainnya. Mengapa gerangan? la memberi beberapa sebab. Pertama, upaya pembentukan badan antikorupsi terpusat itu rupa-rupanya, biasanya, dibentuk atas dorongan donor tertentu dan bukan tuntutan yang jelas dari warga negara. Fakta apa yang lazim muncul mengikutinya? $\mathrm{Ya}$, donor itulah yang malah lazim memotivasi pemerintah untuk hanya membentuk lembaga yang alakadarnya saja alias lemah. Artinya hanya sekadar untuk memenuhi persyaratan minimum yang ditentukan oleh negara donor.

Kedua, bahwa ukuran negara-negara dunia ketiga yang berusaha mengadopsi model pemberantasan korupsi di Singapura dan Hongkong, umumnya memiliki keluasan pemerintahan di pusat maupun bawahan, ditambah lagi dengan faktor-faktor demografik seperti keanekaragaman etnis yang menurut Michael Ndichu Kuria dapat dengan mudah meregangkan sumber daya badan antikorupsi yang terpusat justru ke lahan-lahan yang tidak terkelola, tetapi dengan tetap berkicau sukses. Badan itu 
misalnya tetap berkiprah seolah berhasil, meski jika dengan jujur diaufit, ia hanya menjadi semacam bunga-bunga politik penegakan hukum dalam suatu negara yang sama sekali tidak efektif. Badan dengan historis semacam itu akan dengan sendirinya menghindari sejumlah pantangan yang digariskan oleh bigg boss penentu politik di negeri itu.

Ketiga, absennya faktor kejujuran politik. Amat sukar menemukan kemauan politik untuk menyediakan sumber daya dan independensi yang cukup kepada badan antikorupsi yang baru dibentuk. Malah, lucunya, menurut Michael Ndichu Kuria, sebagian besar dari agen terpusat ini melapor kepada pejabat yang sama yang seharusnya mereka selidiki atas kesulitan-kesulitan manajemen dan keuangannya. Jadi dapat dibayangkan jika nafas badan pemberantasan korupsi itu sendiri ditentukan oleh pihak-pihak koruptif yang mestinya sesegera mungkin justru seyogyanya harus dikirim ke lembaga pemasyarakatan.

Negara dengan kepahitan pengalaman seperti itu tak pernah mampu membuat prioritas kerja yang benar dan jujur. José Ugaz, Ketua Transparansi Internasional, ketika mengantar terbitan hasil survei Indeks Persepsi Korupsi 2016 sengaja menyoroti hubungan antara korupsi dan ketimpangan, yang saling menyokong satu sama lain untuk menciptakan lingkaran setan antara korupsi, distribusi kekuasaan yang tidak merata di masyarakat, dan distribusi kekayaan yang tidak merata. Tetapi hal seperti ini akan dianggap pantang untuk menjadi prioritas kerja. Padahal di banyak negara, kata José Ugaz, orang telah kehilangan sebagian besar kebutuhan dasarnya dan tidur kelaparan setiap malam karena korupsi, sementara yang berkuasa dan korup menikmati gaya hidup mewah tanpa hukuman.

José Ugaz juga menyoroti retorika dan populisme kepemimpinan sebagai malapaetaka baru. la berkata "Keterkaitan korupsi dan ketidaksetaraan juga memberi andil besar atas kemunculan pola kepemimpinan populisme. Ketika politisi tradisional gagal mengatasi korupsi, orang-orang menjadi sinis. Semakin banyak orang beralih ke pemimpin populis yang berjanji untuk memutus siklus korupsi dan hak istimewa. Namun ini cenderung memperburuk - daripada menyelesaikan - ketegangan yang memberi andil besar atas gelombang populisme yang tak menghasilkan sesuatu kecuali ilusi belaka. Kutipan berikut menjelaskannya.

"Corruption and social inequality are indeed closely related and provide a source for popular discontent. Yet, the track record of populist leaders in tackling this problem is dismal; they use the corruption-inequality message to drum up support but have no intention of tackling the problem seriously. But, first, let's look at what corruption has to do with inequality and vice versa".

(https://Www.transparency.org/news/feature/corruption_and_inequality_how_populists_mislead_peopl e).

Keempat, percaya atau tidak, badan antikorupsi terpusat sebetulnya memberi politisi satu target pasti untuk dimanipulasi dan terhalang agar tidak mengekspos skema korup mereka. Ini sangat masuk akal, karena semua upaya korupsi dikoordinasikan oleh satu tubuh, semua upaya anti-korupsi dapat dengan mudah digagalkan dengan mengganggu operasinya.

Kelima, sebuah lembaga terpusat yang baru dibentuk tentulah memerlukan seperangkat undangundang baru, infrastruktur baru, staf baru dan pembentukan birokrasi baru, yang dengan sendirinya memakan waktu lama. la akan asyi berteriak dan berlagak dalam seputaran isyu-isyu ini. Bila semua yang diperlukannya tidak diberikan dalam jumlah atau kualitas yang tepat, badan itu pun tidak dapat mencapai tujuannya. la akan loyo. Macan kertas. Tukang ngarang dan bermain dalam retorika akalakalan belaka.

Hal lain yang begitu merisaukan namun kerap diabaikan begitu saja ialah "State capture, grand corruption and the death of democracy". Catatan kuat pada laporan Indeks Persepsi Korupsi 2016 menyebutkan bahwa "Ketidaksamaan ekonomi ekstrim dan penangkapan politik terlalu sering saling bergantung. Waktu tidak terkendali, institusi politik dirongrong dan pemerintah sangat melayani kepentingan elit ekonomi hingga merugikan orang biasa. Dengan kata lain, korupsi dapat berkembang ketika elit mengendalikan tuas kekuasaan tanpa pertanggungjawaban apapun."

Demokrasi itu memang bermacam-macam, terserah bagaimana sebuah negara mengklaimnya untuk dirinya. Bahak deokrasi pun bisa membungkus praktik kediktatoran. Tetapi kepalsuan demokrasi dapat 
dibangun oleh kekuatan politik, tentu saja. Kalau begitu apa gunanya lembaga antikorupsi pada negeri seperti itu? Tak lain kecuali untuk alat politik belaka.

Penulis dosen FISIP UMSU. Koordinator Umum Pengembangan Basis Sosial Inisiatif \& Swadaya ('nBASIS)

https://id.wikipedia.org/wiki/Marah_Halim_Harahap

http://www.rmolsumsel.com/read/2015/12/04/41274/Selamat-Jalan-Pak-Marah-Halim...Kepemimpinanmu-Jadikan-Sumut-Disegani-

http://m.rmolsumsel.com/news.php?id=41274

http://www.imgrum.org/user/igsumut/1905549197/1055614542043781793 1905549197

http://archive.li/AxWBt 